\title{
Pencegahan Tindak Kejahatan Pencurian dengan Alarm Anti Maling Sederhana di Lingkungan Masyarakat
}

\author{
Ria Asep Sumarni ${ }^{1 *}$, Siti Ayu Kumala ${ }^{1}$ dan Irnin Agustina Dwi Astuti ${ }^{1}$ \\ ${ }^{1}$ Universitas Indraprasta PGRI, Jalan Nangka Raya No. 58 C, RT.5/RW.5, Tanjung Barat, Jagakarsa, Jakarta \\ Selatan, Indonesia \\ *Email korespondensi: riaasepsumarni@gmail.com
}

\begin{abstract}
Abstrak
Keamanan dan keyamanan adalah harapan hidup seluruh manusia. Saat ini banyak sekali perumahanperumahan yang mempunyai sistem keamanan yang sangat bagus. Dilengkapi dengan security, CCTV dan alarm anti maling, dengan harapan untuk meningkatkan keamanan komplek. Akan tetapi, tidak sedikit juga perumahan yang tidak memiliki sistem keamanan yang memadai. Alarm peringatan maling saat ini sangat dbutuhkan untuk sistem keamanan rumah, namuun tidak semua orang dapat membelinyakarena harganya yang relative mahal. Mengangkat permasalahan diatas, maka kami melakukan kegiatan pengabdian masyarakat berupa pelatihan pembuatan alarm anti maling sederhana yang akan di laksanakan di komplek perumahan Pamulang Park Residence. Metode pelaksanaan pengabdian kepada masyarakat adalah sosialisasi dan pelatihan. Hasil produk pelatihan ini dalam bentuk alat alarm anti maling sederhana yang dapat dipasang di rumah masing-masing warga Pamulang Park residence.
\end{abstract}

Kata kunci: Alarm Anti Maling, Pencegahan Tindak Kejahatan, Alat Peraga.

\begin{abstract}
Security and security are the life expectancy of all humans. At present there are a lot of housing that has a very good security system. Equipped with security, CCTV and anti-theft alarms, with the hope of increasing the security of the complex. However, there are not a few housing that do not have adequate security systems. The burglar warning alarm is currently very needed for home security systems, but not everyone can buy because the price is relatively expensive. Raising the above problems, we conducted community service activities in the form of a simple anti-theft alarm training training that will be carried out in the Pamulang Park Residence housing complex. The method of implementing community service is socialization and training. The results of this training product are in the form of a simple anti-theft alarm device that can be installed in the homes of each of the residents of Pamulang Park residence
\end{abstract}

Keywords: Bulgar Alarm, Prevention of Crime, Experimental Tool.

Format Sitasi: Sumarni, R. A., Kumala, S.A., \& Astuti, I.A.D. (2019). Pencegahan Tindak Kejahatan Pencurian dengan Alarm Anti Maling Sederhana di Lingkungan Masyarakat. Jurnal Solma, 8(2), 348355. Doi: http://dx.doi.org/10.29405/solma.v8i2.3037

Diterima: 06 Februari 2019 | Revisi: 20 April 2019 | Dipublikasikan: 21 Oktober 2019

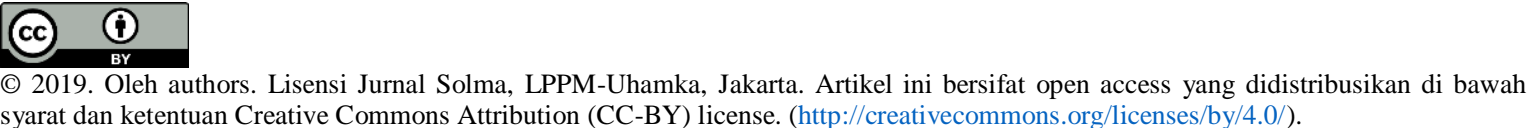
syarat dan ketentuan Creative Commons Attribution (CC-BY) license. (http://creativecommons.org/licenses/by/4.0/). 


\section{PENDAHULUAN}

Lingkungan yang nyaman dan aman merupakan harapan semua orang dalam memilih tempat tinggal. Pada dasarnya, rumah membuat penghuninya merasa aman, nyaman dan tenang tinggal di dalamnya. Terlepas seberapa besar atau kecil rumah tersebut. Rumah yang sehat tidak hanya memberikan dampak positif bagi penghuninya, namun juga menyebarkan aura positif disekitarnya (Adrian, 2015). Saat ini banyak sekali perumahanperumahan yang mempunyai sistem keamanan yang sangat bagus. Dilengkapi dengan security, CCTV dan alarm anti maling dengan harapan untuk meningkatkan keamanan komplek. Alarm anti maling juga saat ini semakin sering digunakan di rumah, kantor, pusat perbelanjaan dan lain sebagainya (Ahmed, Mohammed, \& Agbo, 2006). Akan tetapi, tidak sedikit juga perumahan yang tidak memiliki sistem keamanan yang memadai.

Definisi alarm secara umum yaitu sebagai bunyi peringatan atau pemberitahuan yang digunakan untuk memperingatkan operator adanya bahaya pada jaringan dalam bentuk sinyal, bunyi atau sinar (Wikipedia, 2015).Selain mampu mendeteksi tindakan pencurian atau bahaya lainnya, alarm juga mampu mengeluarkan reaksi panik pada seseorang yang menyebabkan seseorang membahayakan dirinya sendiri saat menyelamatkan diri, maka dari itu penggunaan alarm harus ditempatkan pada tempat yang strategis sehingga dapat dengan cermat mendeteksi kemungkinan adanya bahaya (Satria \& Suraatmadja, 2013).

Ada beberapa rancangan alarm anti maling yang sudah dibuat, seperti perancangan alarm anti maling yang dibuat oleh mahasiswa-mahasiswi Universitas Negeri Semarang dengan membuat rangkaian sensor PIR, dengan output berupa suara sirine dan dihubungkan langsung dengan telepon genggam agar saat rangkaian sensor mendeteksi adanya maling, telepon langsung menghubungi satpam atau nomor yang telah dituju (Hapsari, 2018).

Perancangan alat alarm anti maling berikutnya dibuat oleh mahasiswa-mahasiswi Universitas Sumatera Utara yang hampir sama dengan contoh sebelumnya hanya saja komponen utamanya adalah sebuah sensor berupa komponen photodiode, infrared, dan IC 7432, sedangkan untuk indikator digunakan LED dan Speaker. LED (Light Emitting Diode) sendiri terbuat dari material setengah penghantar campuran seperti, gallium arsenida fosfida (GaAsP), gallium fosfida $(\mathrm{GaP})$, dan gallium aluminium arsenida (GaAsP) (Pamungkas, 2011). Rangkaian alarm ini dapat berbunyi ketika LED terkena cahaya, maka akan berbunyi, sedangkan ketika LED tidak terkena cahaya maka alarm tidak akan berbunyi (Laurent, G., 2016). 
Penelitian yang dilakukan oleh Saleh, M. \& Haryanti (2017) menjelaskan sistem keamanan rumah menggunakan relay. Relay merupakan saklar yang dioperasikan secara elektrik (Pamungkas, 2011). Sistem keamanan menggunakan relay, pemilik rumah akan mendapatkan peringatan dari lampu rumah dan suara alarm. Apabila sistem keamanan di hidupkan dengan cara menekan push button hijau, maka relay akan aktif (Herlan, 2015). Dan menurut (Yohana, 2013) apabila pintu rumah terbuka sebesar 25-90 derajat, maka semua lampu rumah dan alarm akan berubah ke posisi 1 atau aktif.

Salah satu komplek perumahan yang belum dilengkapi dengan alarm anti maling adalah perumahan Pamulang Park Residence di Tangerang Selatan. Di perumahan ini meskipun sudah terdapat 2 pos security dengan satu pintu masuk dan keluar, tetapi masih terjadi pembobolan rumah di siang hari. Hal ini karena sistem keamanan di setiap rumah kurang dilengkapi dengan CCTV maupun alarm anti maling. Dimana kejadian pembobolan terjadi siang hari disaat banyak warga komplek yang bekerja dan ibu-ibu komplek menjemput anak pulnag sekolah. Sehingga peluang terjadinya pembobolan itu ada dikarenakan kondisi komplek yang sepi.

Mengangkat permasalahan di atas, maka kami ingin melakukan kegiatan pengabdian masyarakat berupa pelatihan pembuatan alarm anti maling sederhana yang akan di laksanakan di komplek perumahan Pamulang Park Residence. Harapan kami dari pelatihan ini warga dapat membuat alarm anti maling sederhana yang dapat dipasang di rumah warga.

\section{MASALAH}

Masalah pokok dalam pengabdian masyarakat ini adalah kurangnya sistem keamanan di komplek perumahan serta lingkungan yang sepi membuat peluang terjadinya pembobolan di komplek. Oleh sebab itu, kami ingin melakukan pelatihan pembuatan alarm anti maling sederhana yang dapat dibuat sendiri dan dapat dipasang di rumah warga. Diharapkan dengan kegiatan ini dapat membantu warga dalam meningkatkan keamanan komplek. Kegiatan abdimas ini memiliki target antara lain yaitu masyarakat mengetahui cara pembuatan alarm anti maling sederhana dan masyarakat dapat membuat alarm anti maling sederhana untuk rumahnya masing-masing.

\section{METODE PELAKSANAAN}

Metode pelatihan dan pendampingan serta diskusi merupaka metode yang digunakan dalam pelatihan ini. Pelatihan dilakukan dengan cara memberikan sosialisasi materi 
tentang pembuatan alarm anti maling sederhana, kemudian peserta/masyarakat dilatih untuk membuat alarm anti maling sederhana yang bertujuan untuk pencegahan kejahatan di rumah masing-masing. Materi yang diberikan saat pelatihan meliputi langkah pembuatan dan pemanfaatan alarm anti maling sederhana.

Kemudian tim menyiapkan alat dan bahan yang akan digunakan dalam merangkai alat alarm anti maling sederhana. Bahan ajar atau modul juga disiapkan untuk menunjang kagiatan abdimas dan membantu peserta abdimas dalam merangkai alat. Satu hari sebelum hari pelaksanaan abdimas, tim mengadakan rapat kegiatan abdimas untuk membahas halhal yang perlu disiapkan. Rapat ini dihadiri oleh tim abdimas yaitu, Ria Asep Sumarni, Siti Ayu Kumala, dan Irnin Agustina Dwi Astuti dan dua orang mahasiswa, Danang Aji dan Niko Prayoga Wiratama yang bertugas sebagai trainer membantu saat pelaksanaan abdimas.

Pelaksanaan kegiatan ini dilakukan dalam tiga tahap, yaitu tahap persiapan, pelaksanaan, dan evaluasi. Tahap pertama adalah tahap persiapan. Dalam tahap ini tim melakukan survei pendahuluan untuk mengetahui kondisi target kegiatan dengan menganalisis kondisi tempat yang akan digunakan, kondisi warga yang akan diberikan pelatihan, dan menyusun rancangan kegiatan yang akan dilakukan. Tahap kedua yaitu tahap pelaksanaan. Tim melakukan pelatihan alarm anti maling sederhana yang ditujukan untuk seluruh warga Pamulang Park Residence. Kegiatan pelatihan ini dilakukan agar warga bisa membuat alarm anti maling sederhanauntuk meningkatkan keamanan rumah. Tahap ketiga adalah evaluasi. Evaluasi kegiatan ini dilakukan terhadap proses kegiatan. Evaluasi berkaitan selama kegiatan berlangsung dari tahap persiapan sampai tahap pelaksanaan, yang meliputi keadaan komplek, kehadiran peserta pelatihan, antusias peserta saat mengikuti kegiatan, dan saran atau kritik terhadap kegiatan.

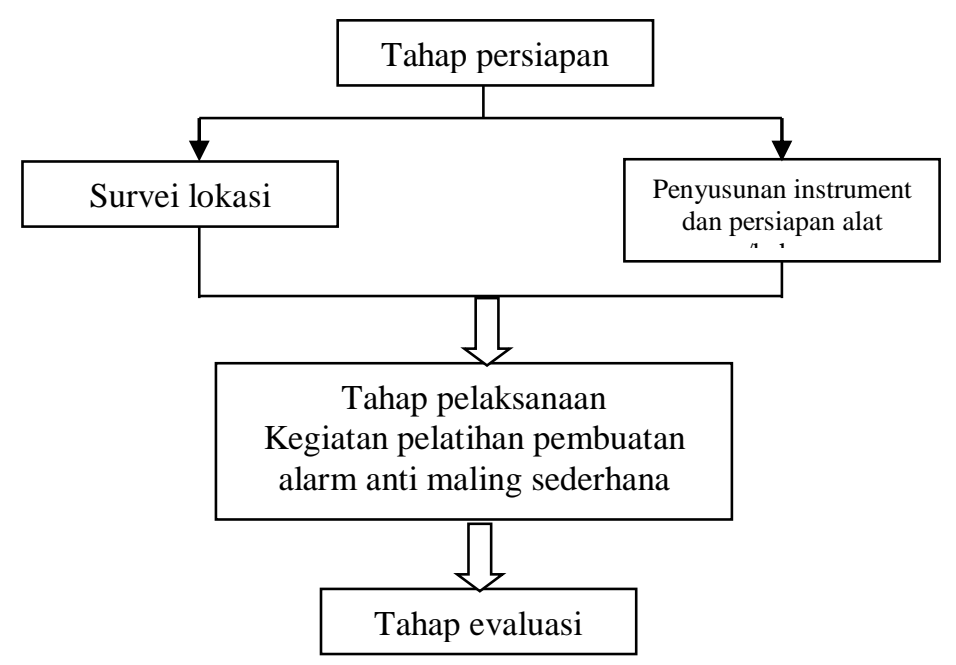


Gambar 1. Diagram alur kegiatan pengabdian masyarakat

\section{PEMBAHASAN}

Kegiatan dilaksanakan dalam dua tahap sosialisasi dan pelatihan. Pelaksanaan kegiatan ini pada tanggal 19 dan 25 November 2018. Selanjutnya, dilanjutkan dengan pelaksanaan kegiatan yang diawali dengan acara pembukaan oleh ketua kegiatan yaitu Bapak Ria Asep Sumarni, M.Pd.Si. Kegiatan berlangsung di Pamulang Park Residence dalam bentuk ceramah diskusi dan praktek keterampilan dalam membuat alat alarm anti maling sederhana. Kegiatan sosialisasi mengenai pentingnya keamaan rumah di lingkungan perumahan dibawakan oleh Siti Ayu Kumala, M.Sc. sebagai narasumber.

Metode yang digunakan untuk mencapai tujuan adalah metode diskusi dan praktek (learning by doing). Menurut Jhon Deway learning by doing merupakan belajar melalui perbuatan langsung yang dilakukan secara aktif, baik individual maupun kelompok (Suryo, 1984). Menurut (Ansori, 2010) learning by doing memili metode yaitu metode proyek. Dimana metode ini sangat mungkin diterapkan karena metode proyek merupakan salah satu cara pemberian pengalaman belajar dengan menghadapkan pada persoalan sehari-hari untuk dipecahkan secara kelompok Gabungan kedua metode tersebut diharapkan mampu meningkatkan pemahaman dan keterampilan khalayak berkaitan dengan keterampilan dalam membuat alat alarm anti maling sederhana.

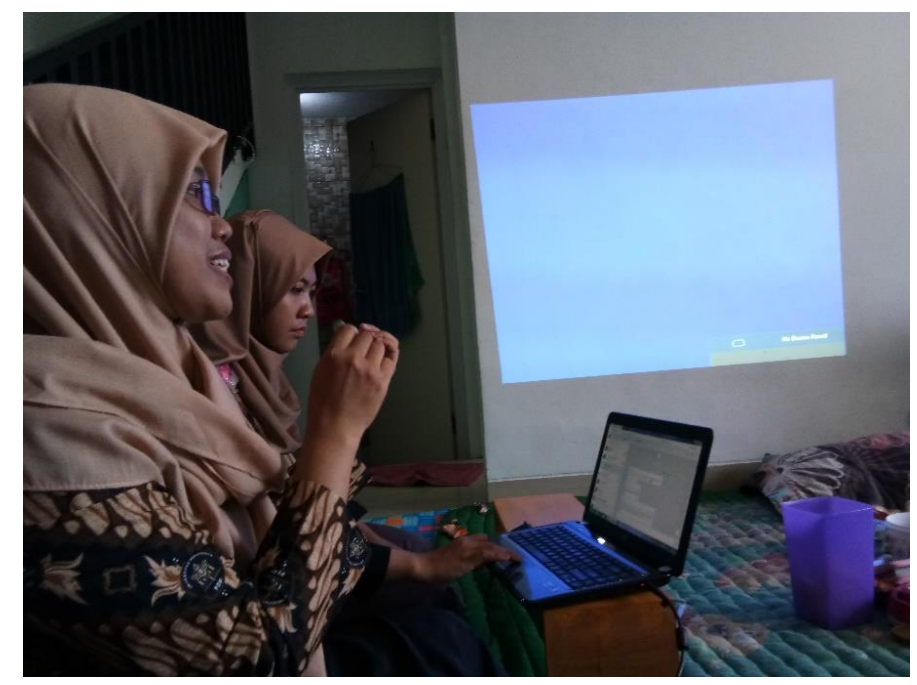

Gambar 2. Kegiatan sosialisasi abdimas

Pada tanggal 25 November 2018 dilanjutkan dengan kegiatan on service dalam bentuk praktik. Kegiatan praktek ini diikuti oleh peserta sebanyak 21 warga Pamulang Park Residence. Dalam kegiatan praktik, peserta diberi pelatihan membuat alat alarm anti maling sederhana. Alat dan bahan yang diperlukan yaitu resistor, buzzer, transistor, LED, 
laser, batu baterai, kabel listrik, dan timah. Alat dirangkai sesuai dengan desain rangkai seperti pada gambar 3. Rangkaian tersebut memiliki beberapa rangkaian dan fungsi yang diungkapkan oleh beberapa ahli mengenai resistor, LDR, buzzer serta transistor. Secara umum Kalsum \& Rosdiana (2011) menjelaskan bahwa resistor merupakan komponen dasar elektronika yang digunakan untuk membatasi jumlah arus yang mengalir dalam suatu rangkaian kemudian, menurut (Rohmanu \& Widiyanto, 2018) buzzer listrik ialah sebuah komponen elektronika yang dapat mengubah sinyal listrik menjadi getaran suara. Pamungkas (2011) mengungkapkan bahwa LDR dibuat dari bahan semikonduktor beresistansi tinggi yang tidak dilindungi dari cahaya dan transistor merupakan Transistor merupakan salah satu komponen aktif karena dapat memperkuat suatu sinyal masukan dan menghasilkan suatu sinyal keluaran yang lebih besar (Rahardjo, 2014).
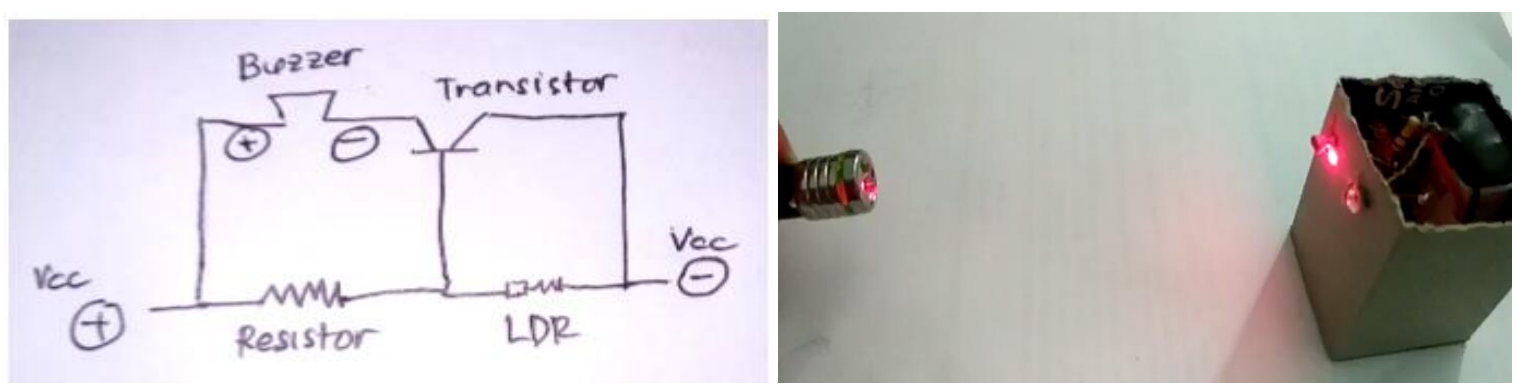

Gambar 3. Rangkaian alat alarm anti maling sederhana dan alat alarm anti maling sederhana

Setelah semua alat dan bahan dirangkai sesuai dengan desain rangkaian (gambar 3), kemudian rangkaian alat tersebut dihubungkan ke laser dan batu baterai. Selanjutnya diuji coba dengan cara menyalakan lampu laser dan laser tersebut dihalangi oleh suatu benda atau bisa juga telapak tangan untuk mencobanya. Berdasarkan penelitian yang dilakukan Rahardjo (2014) bahwa apabila sebuah sensor sentuh telah tersentuh oleh kulit manusia, maka salah satu kanal keluaran (piezoelectric) buzzer akan langsung berbunyi dan LED juga akan langsung menyala.

Langkah kegiatan abdimas selanjutnya adalah evaluasi. Kegiatan evaluasi yang dilaksanakan meliputi persiapan, pelaksanaan, kehadiran peserta abdimas, tanggapan dan respon peserta abdimas, dan rangkaian alat alarm anti maling sederhana. Secara umum, kegiatan abdimas ini terselenggara cukup baik, hanya ada beberapa kendala pada saat pelaksanaannya. Kendala tersebut diantaranya terdapat beberapa peserta yang gagal dalam merangkai alat. Kondisi seperti ini dikarenakan kegiatan merangkai alat elektronika ternilang cukup sulit terutama pada saat menggabungkan rangkaian alat satu ke yang 
lainnya. Kadang rangkaian tersebut mudah lepas jika tidak terlalu kencang untuk merekatkannya. Kendala yang kedua yaitu minimnya solder, karena hanya terdapat 4 solder dalam kegiatan pelatihan membuat alat, maka harus bergantian antara kelompok satu dengan yang lainnya. Ini membuat peserta lama dalam merangkai alat dan memakan waktu, sehingga waktu dalam pelatihan dan praktik merangkai alat mengalami penambahan sekitar 2 jam.

\section{KESIMPULAN}

Program pengabdian kepada masyarakat ini telah dilaksanakan dengan baik dengan harapan terciptanya kondisi lingkungan yang bebas dari tindak kejahatan seperti pencurian di daerah Pamulang Park Residence dengan cara membuat alat alarn anti maling sederhana. Kegiatan yang dilakukan telah memberikan pemahaman kepada warga untuk dapat membuat alat alarm anti maling dengan alat yang sederhana, mudah dirangkai, dan harga yang ekonomis. Berdasarkan hasil dan kesimpulan di atas, saran yang dapat diajukan antara lain warga dapat mengembangkan alat alarm anti maling dengan bantuan audio atau sensor gerak sehingga alat alarm yang dibuat bisa lebih canggih dan inovatif lagi.

\section{UCAPAN TERIMA KASIH}

Terima kasih ditujukan kepada LPPM Universitas Indraprasta PGRI yang telah memberikan dana hibah kegiatan Pengabdian kepada Masyarakat. Dan juga berterima kasih kepada bapak/ibu masyarakat Pamulang Park Residence yang sudah berpartisipasi dalam kegiatan ini.

\section{DAFTAR PUSTAKA}

Adrian, A. (2015). Lingkungan Rumah Ideal. Temu Ilmiah IPLBI, 57-62.

Ahmed, M. S., Mohammed, A. S., \& Agbo, G. A. (2006). Development of a Simple Sound Activated Burglar Alarm System. Leonardo Journal of Science, (9), 97-102.

Ansori, A. (2010). Hubungan antara Kecerdasan Emosional dengan Keberagamaan Remaja Masjid (IREMA) Desa Margorejo Kec. Margorejo Kab. Pati Tahun 2010 (pp. 80-81). pp. 80-81. Pati: STAI.

Hapsari, M. A. Usulan Program kegiatan Mahasiswa "Alarm Rumah Bebas Maling Berbasis Sensor PIR, Telepon Otomatis dan Sirine. , (2018).

Herlan, M. (2015). Push Bottom. Jawa Timur: Politeknik Negeri Surabaya.

Kalsum, T. U., \& Rosdiana. (2011). Alat Penghapus Whiteboard Otomatis Menggunakan Motor STTEPER. Jurnal Media Infotama, 7(1), 38-55. 
Laurent, G., C. (2016). Laporan Alrm anti Maling. Retrieved from www.researchgate.net

Pamungkas, W. (2011). Aplikasi Sensor Cahaya Untuk Alarm Anti Pencuri. Journal Infotel, 3(2), 50-59. https://doi.org/10.20895/infotel.v3i2.95

Rahardjo, P. (2014). Pengaman Benda-Benda Suci Pratima di Pura dari Tindakan Pencurian dengan Menggunakan Alarm Sentuh (Touch Alarm) (pp. 1-40). pp. 1-40. Bali: FT Universitas Udayana.

Rohmanu, A., \& Widiyanto, D. (2018). Sistem Sensor Jarak Aman pada Mobil Berbasis Mikrokontroler Arduino Atmega328. Jurnal Informatika SIMANTIK, 3(1), 7-14.

Saleh, M., \& Haryanti, M. (2017). Rancang Bangun Sistem Keamanan Rumah Menggunakan Relay. Jurnal Teknologi Elektro, 8(2).

Satria, D., \& Suraatmadja, M. S. (2013). Aplikasi Mikrokontroler pada Sistem Keamanan Rumah Berbasis Sensor PIR Terintegrasi dengan Modem dan Alarm. Bandung: Tekom University.

Suryo, B. (1984). Psikologi Pendidikan (Raja Grafi). Jakarta.

Wikipedia. Alarm. , (2015).

Yohana, M. (2013). Alarm Anti Maling. Kupang: FKIP Universitas Nusa Cendana. 